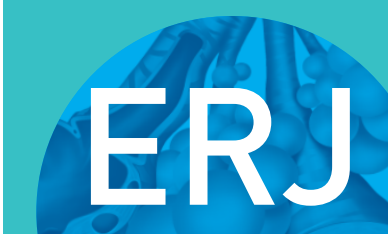

open research
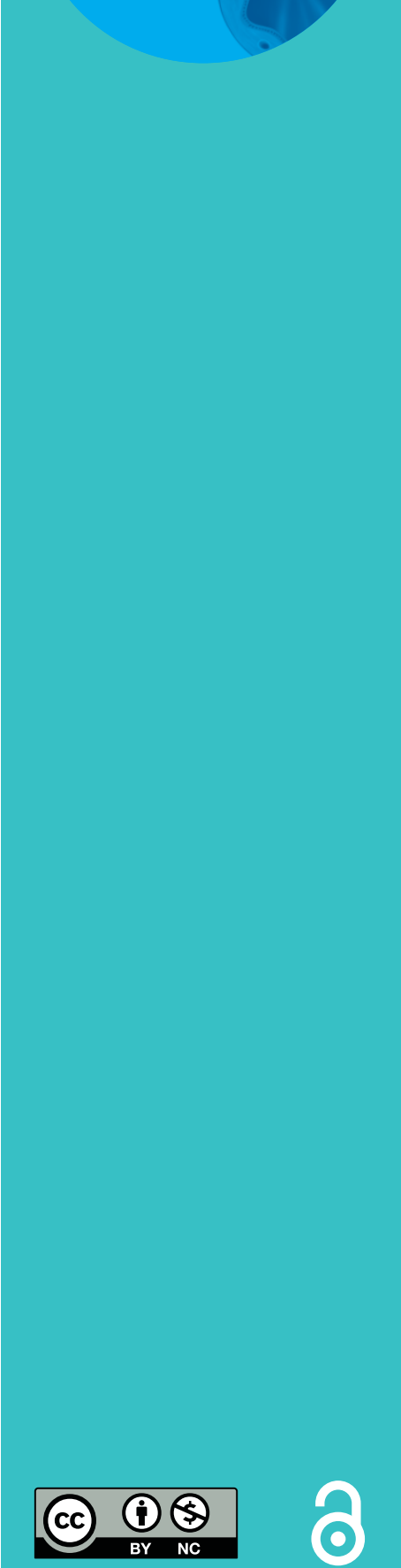

\section{First clinical trials of the inhaled epithelial sodium channel inhibitor BI 1265162 in healthy volunteers}

\author{
Alison Mackie ${ }^{1}$, Juliane Rascher ${ }^{2}$, Marion Schmid ${ }^{1}, V^{2}$ erena Endriss ${ }^{1}$, \\ Tobias Brand ${ }^{1}$ and Wolfgang Seibold ${ }^{1}$
}

Affiliations: ${ }^{1}$ Boehringer Ingelheim, Biberach an der Riss, Germany. ${ }^{2}$ SocraMetrics GmbH, Erfurt, Germany, on behalf of Boehringer Ingelheim Pharma GmbH \& Co. KG, Biberach an der Riss, Germany.

Correspondence: Alison Mackie, Boehringer Ingelheim Pharma GmbH \& Co. KG, Birkendorfer Str. 65 88397 Biberach an der Riss, Germany. E-mail: alison.mackieaboehringer-ingelheim.com

\section{ABSTRACT}

Background: Inhibition of the epithelial sodium channel (ENaC) represents a mutation-agnostic therapeutic approach to restore airway surface liquid hydration and mucociliary clearance in patients with cystic fibrosis. BI 1265162 is an inhaled $\mathrm{ENaC}$ inhibitor with demonstrated preclinical efficacy.

Methods: Three phase I trials of BI 1265162 in healthy male subjects are presented: NCT03349723 (singlerising-dose trial evaluating safety, tolerability and pharmacokinetics (PK)); NCT03576144 (multiple-risingdose trial evaluating safety, tolerability and PK); and NCT03907280 (absolute bioavailability trial).

Results: BI 1265162 single doses $\leqslant 1200 \mu \mathrm{g}$ and multiple doses of $600 \mu \mathrm{g}$ were well tolerated. Adverse events were balanced across treatment groups, were of mainly mild or moderate intensity and resolved by trial-end. One subject discontinued from trial medication on day 7 (asymptomatic hyperkalaemia adverse event; recovered day 8). One subject experienced a serious adverse event (neuropathia vestibularis) leading to hospitalisation and missed one of the four dosing periods. Both events were not considered to be drugrelated and subjects recovered. BI 1265162 displayed dose-proportional, time-independent PK; maximum accumulation was 1.6-fold; calculated effective elimination half-life was 3.6-8.7 h over the dose ranges tested. Renal excretion was not a major drug elimination route. Oral and inhaled dosing ( \pm activated oral charcoal) absolute bioavailability was $0.50 \%$ and $\sim 40 \%$, respectively.

Conclusion: BI 1265162 single or multiple doses up to 6.5 days were well tolerated. Systemic exposures mainly represent drug absorbed through the lungs and not the gastrointestinal tract, with $\sim 40 \%$ of the inhaled dose reaching the systemic circulation. Accumulation was minimal. Twice-daily dosing is supported for future development.

@ERSpublications

Cell and animal studies have demonstrated that BI 1265162 is a potent ENaC inhibitor. Three phase I trials show that single- and multiple-dose BI 1265162 is safe. BI 1265162 is being tested in phase II studies, using twice-daily dosing, in people with CF. https://bit.ly/3nPUkrO

Cite this article as: Mackie A, Rascher J, Schmid M, et al. First clinical trials of the inhaled epithelial sodium channel inhibitor BI 1265162 in healthy volunteers. ERJ Open Res 2021; 7: 00447-2020 [https://doi.org/10.1183/23120541.00447-2020].

This article has supplementary material available from openres.ersjournals.com.

Received: 29 June 2020 | Accepted after revision: 17 Nov 2020

Copyright $\odot$ ERS 2021. This article is open access and distributed under the terms of the Creative Commons Attribution Non-Commercial Licence 4.0. 


\section{Introduction}

Cystic fibrosis (CF) is a multisystem disorder caused by mutations in the cystic fibrosis transmembrane conductance regulator gene (CFTR). This can lead to defects in the CFTR protein [1], causing aberrant chloride transport in epithelial tissues resulting in alterations to the hydration and $\mathrm{pH}$ of airway surface liquid (ASL) $[2,3]$.

Over the past decade, significant clinical progress has been made to directly target CFTR mutations to increase the quantity and/or enhance the function of the protein [3]. However, even with the arrival of the new triple CFTR modulator Trikafta ${ }^{\mathrm{TM}}$ (ivacaftor, tezacaftor, elexacaftor), which is suitable for patients with at least one F508del mutation, $\geqslant 10 \%$ of patients with CF still remain untreated due to unsuitable genotype $[4,5]$. Furthermore, CFTR modulators restore 10-50\% of CFTR function [6-8] and patients may continue to have exacerbations [4]. Therefore, alternative or additional approaches to therapy, including modulating alternative targets that compensate for CFTR dysfunction, are needed beyond CFTR modulation [2].

One such target is the epithelial sodium channel $(\mathrm{ENaC}) . \mathrm{ENaC}$ is expressed in the conducting airways, alveolar airspaces and the distal colon, and highly expressed in the cortical collecting duct of the kidney. Through sodium and water resorption, and chloride secretion, ENaC and CFTR together maintain a finely tuned homeostatic mechanism to keep ASL hydrated and allow mucociliary clearance, needed for a sterile lung environment $[9,10]$. $\mathrm{ENaC}$ is hyperactivated in $\mathrm{CF}$ and leads to increased absorbance of sodium ions [11-13] and water resorption from the epithelial luminal surface, causing dehydrated mucus and compressed cilia, resulting in poor mucociliary clearance [14].

$\mathrm{ENaC}$ inhibition represents a mutation-agnostic therapeutic approach [9] to restore ASL hydration and enhance mucociliary clearance in people with $\mathrm{CF}$. The potential therapeutic value of ENaC inhibition is supported by the observation of slow lung disease progression in CF patients with a mutation in the $\delta$-subunit of $\mathrm{ENaC}$ that causes reduced $\mathrm{ENaC}$ activity [15]. In addition to the mutation-agnostic property of an ENaC inhibitor, a synergistic effect with CFTR modulators is expected [9]. Indeed, ENaC inhibition further reduced transepithelial water absorption in both CF and normal airway cultures treated with CFTR modulators [16].

No previous potential $\mathrm{ENaC}$ inhibitor therapy has succeeded in clinical trials, probably due to lack of potency, inadequate dosing and/or deposition by inhalation in patients with chronic CF lung disease, induced hyperkalaemia, short study duration, non-study-related exacerbations or lack of end-point sensitivity [17]. Historically, small-molecule direct inhibitors have formed the large part of the clinical development programme. Amiloride failed phase II studies due to efficacy issues [18], and the second- and third-generation amiloride derivatives benzamil [19] and GS-9411 [20] failed preclinical and phase I studies, respectively, due to efficacy issues and hyperkalaemia, respectively. BI 443651 failed phase I due to palatability issues (NCT02706925). VX-731, in combination with the CFTR modulator ivacaftor/lumacaftor, failed phase II (NCT02709109). Likewise, QBW276 was terminated during phase II for strategic reasons (NCT02566044). Camostat, a small-molecule inhibitor of prostatin (a channel-activating protease that is a major regulator of $\mathrm{ENaC}$ activity), failed in phase II due to adverse events [21]. Outside of small-molecule inhibitors, the SPLUNC-1 peptide analogue SPX-101 failed phase II due to lack of efficacy (NCT03229252).

BI 1265162 is a small-molecule direct ENaC inhibitor. In rat and sheep studies, no effects on serum potassium and plasma electrolytes were observed, and BI 1265162 demonstrated a markedly higher efficacy than amiloride (a 30-70-fold lower median inhibitory concentration) [16]. Importantly, these studies also demonstrated that the efficacy of BI 1265162 is mutation-agnostic and synergistic with the

This study is registered at www.clinicaltrials.gov with identifier numbers NCT03349723, NCT03576144 and NCT03907280. To ensure independent interpretation of clinical study results, Boehringer Ingelheim grants all external authors access to all relevant material, including participant-level clinical study data, and relevant material as needed by them to fulfil their role and obligations as authors under the International Committee of Medical Journal Editors criteria. Furthermore, clinical study documents (e.g. study report, study protocol and statistical analysis plan) and participant clinical study data are available to be shared after publication of the primary manuscript in a peer-reviewed journal and if regulatory activities are complete and other criteria met per the Boehringer Ingelheim Policy on Transparency and Publication of Clinical Study Data (https://trials.boehringer-ingelheim.com/). Prior to providing access, documents will be examined, and, if necessary, redacted and the data will be de-identified, to protect the personal data of study participants and personnel, and to respect the boundaries of the informed consent of the study participants. Clinical study reports and related clinical documents can also be requested via https://trials.boehringeringelheim.com/. All requests will be governed by a document sharing agreement. Bona fide, qualified scientific and medical researchers may request access to de-identified, analysable participant clinical study data with corresponding documentation describing the structure and content of the datasets. Upon approval, and governed by a data sharing agreement, data are shared in a secured data-access system for a limited period of 1 year, which may be extended upon request. Researchers should use https://trials.boehringer-ingelheim.com/ to request access to study data. 


\begin{tabular}{lccc} 
TABLE 1 Baseline characteristics of all three trials & \\
& SRD trial & MRD trial & Bioavailability trial \\
\hline Subjects & 56 & 50 & 12 \\
Age years & $34.7 \pm 8.8(21-51)$ & $32.8 \pm 6.6(21-45)$ & $36.8 \pm 9.5(23-49)$ \\
Race & $55(98.2)$ & $48(96.0)$ & $12(100)$ \\
$\quad$ White & $1(1.8)$ & $1(2.0)$ & 0 \\
$\quad$ Black/African American & 0 & $1(2.0)$ & 0 \\
$\quad$ Asian & $55(98.2)$ & $50(100)$ & $12(100)$ \\
Hispanic/Latino & $1(1.8)$ & 0 & 0 \\
$\quad$ No & $26.8 \pm 2.3$ & $24.6 \pm 2.8$ & $25.1 \pm 2.6$ \\
Yes & & & \\
BMI kg-m & -2 & &
\end{tabular}

CFTR modulator lumacaftor/ivacaftor [16]. Data from three phase I trials with BI 1265162 in healthy male subjects are presented: 1) a first-in-man, single-rising-dose (SRD) trial evaluating safety, tolerability and pharmacokinetics (PK) of inhaled BI 1265162 (NCT03349723); 2) a multiple-rising-dose (MRD) trial evaluating safety, tolerability and PK of inhaled BI 1265162 (NCT03576144); and 3) a trial determining absolute bioavailability of BI 1265162 following oral and inhaled ( \pm activated charcoal) administration (NCT03907280).

\section{Methods}

A brief summary of methods is provided. For detailed methodology, see the supplementary material.

All three trials enrolled healthy, nonsmoking males aged 18-50 years (with the exception of the MRD trial: age 18-45 years), with a body mass index of $18.5-29.9 \mathrm{~kg} \cdot \mathrm{m}^{-2}$ and normal lung function (forced expiratory volume in $1 \mathrm{~s}$ and forced vital capacity $\geqslant 80 \%$ predicted normal). Inhaled doses of BI 1265162 were administered via the Respimat Soft $^{\bullet}$ Mist $^{\mathrm{TM}}$ inhaler [22]. The trials were carried out sequentially in the order SRD, MRD, bioavailability trial. For the bioavailability trial, lung function was not part of eligibility criteria (table 1). Serum and urine electrolytes in the SRD and MRD trials were closely monitored to mitigate risk of renal $\mathrm{ENaC}$ inhibition, although systemic exposure of BI 1265162 was not expected to reach relevant levels as is observed with orally administered amiloride (an ENaC inhibitor in clinical use as a potassium-sparing diuretic). Changes in serum potassium were monitored as part of dose-escalation criteria in the SRD and MRD trials.

\section{NCT03349723: safety and PK of BI 1265162 in an SRD trial}

This was a single-centre, partially randomised, single-blind, placebo-controlled trial to investigate the safety and tolerability of BI 1265162 following inhaled administration of SRDs ( $3 \mu \mathrm{g}, 10 \mu \mathrm{g}, 30 \mu \mathrm{g}, 100 \mu \mathrm{g}$, $300 \mu \mathrm{g}, 600 \mu \mathrm{g}, 1200 \mu \mathrm{g}$ ) (figure 1a). The secondary objective was the exploration of PK. Plasma samples were taken up to $48 \mathrm{~h}$ post-dose, with the exception of the $1200 \mu \mathrm{g}$ group, where samples were taken up to $72 \mathrm{~h}$ post-dose. Safety, PK parameters and further end-points are detailed in table 2. Descriptive statistics were calculated for all end-points. Palatability and acceptability of inhaled BI 1265162 were assessed 15 min post-dosing using a multiple-choice questionnaire.

\section{NCT03576144: safety and PK of BI 1265162 in an MRD trial}

This single-centre, randomised, double-blind, placebo-controlled trial investigated the safety and tolerability of BI $1265162(10 \mu \mathrm{g}, 30 \mu \mathrm{g}, 100 \mu \mathrm{g}, 300 \mu \mathrm{g}, 600 \mu \mathrm{g})$ following inhaled administration once daily in the morning of days 1 and 8 and twice daily on days 2-7 (figure 1b). Secondary objectives were $\mathrm{PK}$, including dose proportionality and time dependency, following multiple dosing. Descriptive statistics were calculated for all end-points. For PK parameters, dose proportionality was assessed using a power model. Safety, PK parameters and further end-points are detailed in table 2.

\section{NCT03907280: bioavailability of BI 1265162}

This was a four-arm, open-label, randomised, single-dose, three-way crossover trial followed by a fixed treatment in healthy male subjects to investigate the absolute bioavailability of BI 1265162 following oral and inhaled administration, \pm oral activated charcoal given pre- and post-inhalation, with a 1-h intravenous 
a)

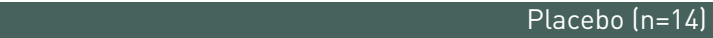
Screening

Day

Drug 1

administration $\uparrow$

Treatment period

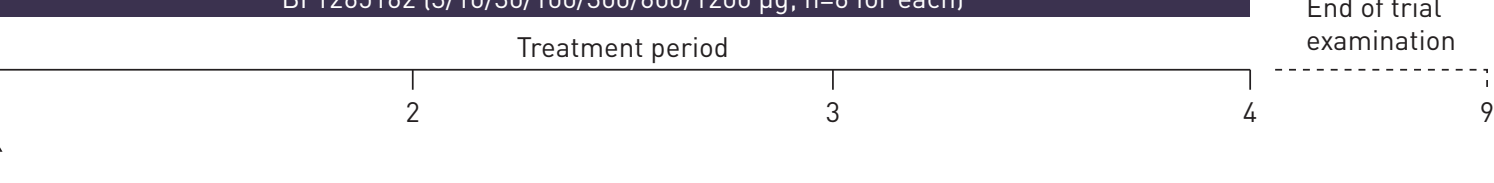

b)

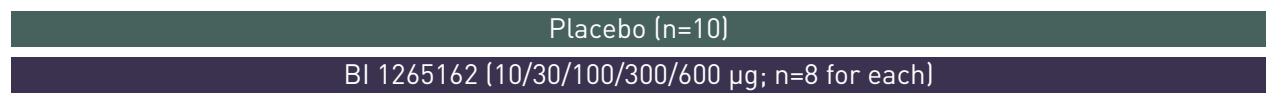

Screening

-

Day

Drug

administration

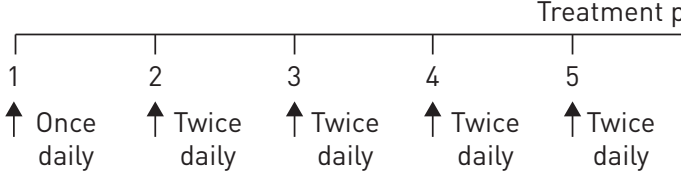

Treatment period

6
$\uparrow$ Twice
daily

7
7 Twice
daily

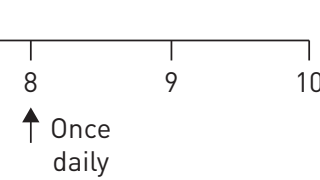

End of trial

examination (-)

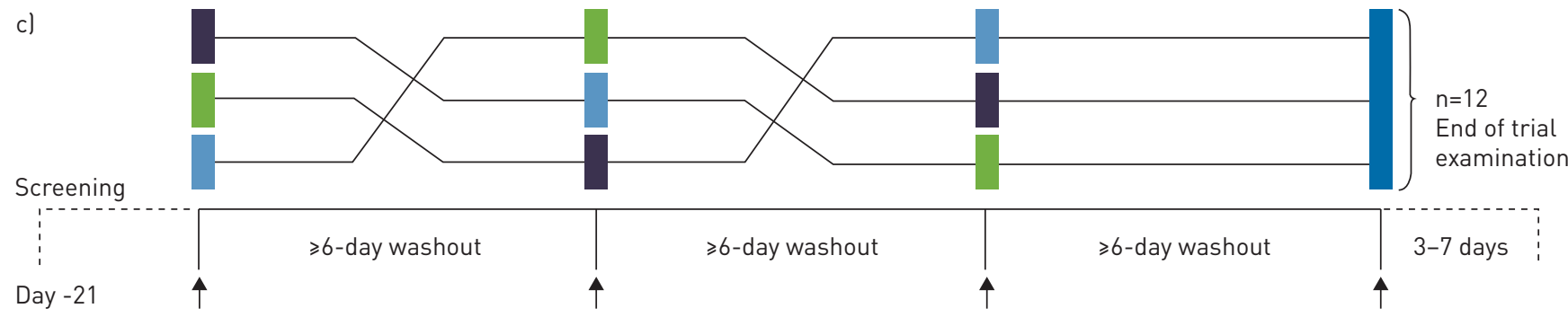

Drug administration

T1: single $1.25 \mathrm{mg}$ oral dose BI 1265162

T2: single $200 \mu \mathrm{g}$ inhaled dose BI 1265162 + oral activated charcoal 15 min pre-dose, 3 min post-dose and $1 \mathrm{~h} 5$ min post-dose

T3: single $200 \mu \mathrm{g}$ inhaled dose BI 1265162 without charcoal

R: single $50 \mu \mathrm{g}$ intravenous infusion BI 1265162 (reference)

FIGURE 1 Trial design of a) the single-rising-dose trial, b) the multiple-rising-dose trial and c) the bioavailability trial. T: treatment; R: reference.

infusion administered as the reference. Safety and PK parameters are detailed in table 2. Safety and further PK end-points were analysed descriptively.

Single doses of BI 1265162 were evaluated: 1) $1.25 \mathrm{mg}$ oral (T1);2) $200 \mu \mathrm{g}$ inhaled with $10 \mathrm{~g}$ of activated charcoal given orally pre- and post-dosing (T2); 3) $200 \mu \mathrm{g}$ inhaled without activated charcoal (T3); and 4) 1-h $50 \mu \mathrm{g}$ i.v. infusion (reference (R)). Subjects were randomly allocated to one of the following treatment sequences: T1-T2-R-T3, R-T1-T2-T3, T2-R-T1-T3 (figure 1c). Each treatment was separated by a $\geqslant 6$-day washout period. Patients were followed-up for 3-7 days post-trial-end.

\section{Results}

Baseline characteristics and safety data are summarised in tables 1 and 3, respectively.

\section{SRD trial}

56 subjects received their assigned single dose of BI 1265162 or placebo and completed the trial according to the clinical trial protocol.

All adverse events were of mild or moderate intensity and resolved by trial-end. Treatment-emergent adverse events (TEAEs) were reported for six (14.3\%) out of 42 subjects treated with BI 1265162 and two $(14.3 \%)$ out of 14 subjects treated with placebo (table 3). Investigator-defined drug-related adverse events occurred in two (4.8\%) out of 42 subjects receiving BI 1265162 and none of the 14 subjects receiving placebo. In the BI $1265162100 \mu \mathrm{g}$ dose group, one (16.7\%) subject reported cough of mild intensity 5 min post-drug administration. In the $300 \mu \mathrm{g}$ BI 1265162 dose group, one subject (16.7\%) had dry eye of mild intensity on the day of drug administration; this adverse event resolved on the next day. No deaths, serious adverse events (SAEs), protocol-specified adverse events of special interest (AESIs) or other significant adverse events were reported in this trial. No other relevant changes were reported in safety laboratory, 


\begin{tabular}{|c|c|c|c|c|}
\hline & Primary end-point(s) & $\begin{array}{l}\text { Secondary } \\
\text { end-point(s) }\end{array}$ & $\begin{array}{l}\text { Further } \\
\text { end-points }\end{array}$ & $\begin{array}{c}\text { Further safety } \\
\text { parameters of interest }\end{array}$ \\
\hline $\begin{array}{l}\text { Single-rising- } \\
\text { dose }\end{array}$ & $\begin{array}{l}\text { Drug-related } \\
\text { adverse events }\end{array}$ & $\begin{array}{l}\mathrm{C}_{\max } \\
\mathrm{AUC}_{0-1}\end{array}$ & $\begin{array}{c}t_{\max } \\
\mathrm{AUC} \mathrm{C}_{0-\infty} \\
\mathrm{CL} / \mathrm{F} \\
t_{1 / 2}\end{array}$ & $\begin{array}{c}\text { Physical examination } \\
\text { Safety laboratory tests } \\
\text { 12-lead ECG } \\
\text { Continuous ECG } \\
\text { monitoring } \\
\text { Vital signs } \\
\text { Spirometry }\left(\mathrm{FEV}_{1}, \mathrm{FVC}\right. \\
\left.\text { and } \mathrm{FEF}_{25-75}\right) \\
\text { Palatability }\end{array}$ \\
\hline $\begin{array}{l}\text { Multiple-rising- } \\
\text { dose }\end{array}$ & Drug-related TEAEs & & & $\begin{array}{l}\text { Physical examination } \\
\text { Safety laboratory tests }\end{array}$ \\
\hline First dose & & $\begin{array}{c}\mathrm{C}_{\max } \\
\mathrm{AUC}_{0-12}\end{array}$ & $\begin{array}{c}t_{\max } \\
t_{1 / 2} \\
f_{\mathrm{e}_{0-12}}\end{array}$ & $\begin{array}{l}\text { Serum and urine } \\
\text { electrolytes } \\
\text { 12-lead ECG }\end{array}$ \\
\hline Last dose & & $\begin{array}{l}C_{\max , s s} \\
A \cup C_{\tau, s s}\end{array}$ & $\begin{array}{c}t_{\max , \mathrm{ss}} \\
\mathrm{RA}_{\mathrm{Cmax}} \\
\mathrm{RA}_{\mathrm{AUC} 0-12} \\
f_{\mathrm{e}_{0-12 s \mathrm{ss}}}\end{array}$ & $\begin{array}{l}\text { Vital signs } \\
\text { Spirometry }\end{array}$ \\
\hline Bioavailability & $A \cup C_{0-\infty}$ & & $\begin{array}{l}\mathrm{C}_{\max }^{0-1255} \\
t_{\max }\end{array}$ & $\begin{array}{c}\text { Physical examination } \\
\text { Safety laboratory tests } \\
\text { 12-lead ECG } \\
\text { Vital signs }\end{array}$ \\
\hline \multicolumn{5}{|c|}{ 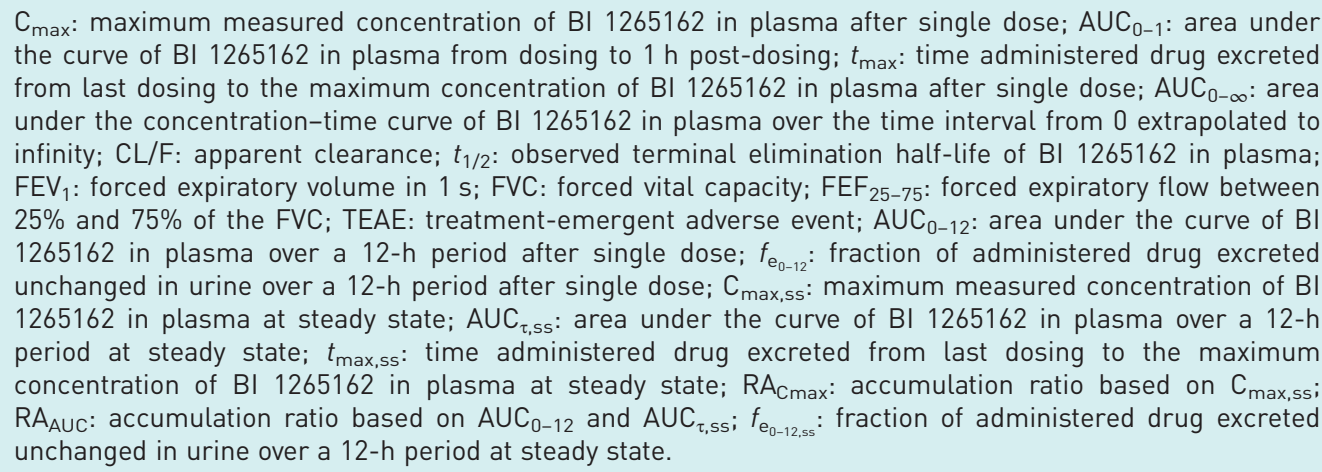 } \\
\hline
\end{tabular}

vital signs, 12-lead ECG, continuous ECG or spirometry values. No relevant changes in plasma or urine electrolytes were detected.

To assess palatability and acceptability, a questionnaire was filled in shortly post-dosing. No relationship was found between dose level and palatability/acceptability. Of subjects reporting a taste (40.5\%), "bitter" was most frequently reported. $98 \%$ of subjects indicated that they would take the medication long term.

\section{MRD trial}

50 subjects entered the MRD trial and received trial medication. In each dose group, eight subjects received BI 1265162 and two received placebo. One subject in the BI $1265162300 \mu \mathrm{g}$ dose group discontinued from trial medication on day 7 due to hyperkalaemia according to protocol. All other subjects were treated as planned and completed the trial.

All adverse events were of mild or moderate intensity and resolved by trial-end. TEAEs were reported for $14(35 \%)$ out of 40 subjects treated with BI 1265162 and one (10\%) out of 10 subjects treated with placebo (table 3). Investigator-defined drug-related adverse events were reported in 11 (27.5\%) out of 40 subjects receiving BI 1265162 and none of the 10 subjects receiving placebo. The most frequently reported drug-related TEAE in subjects receiving BI 1265162 was oropharyngeal pain (three (7.5\%) out of 40). Diarrhoea, dyspepsia, dizziness and cough were each reported as drug-related TEAEs in two (5.0\%) out of 40 subjects receiving BI 1265162. 


\begin{tabular}{|c|c|c|c|c|c|c|c|c|c|c|c|c|}
\hline & \multirow[t]{2}{*}{ Placebo } & \multicolumn{11}{|c|}{ BI 1265162} \\
\hline & & $3 \mu \mathrm{g}$ & $10 \mu \mathrm{g}$ & $30 \mu \mathrm{g}$ & $100 \mu g$ & $300 \mu g$ & $600 \mu g$ & $1200 \mu \mathrm{g}$ & $\begin{array}{l}1.25 \mathrm{mg} \\
\text { oral } \\
\text { solution }\end{array}$ & $\begin{array}{c}200 \mu \mathrm{g} \\
\text { inhaled, } \\
\text { with } \\
\text { activated } \\
\text { charcoal }\end{array}$ & $\begin{array}{c}200 \mu \mathrm{g} \\
\text { inhaled, } \\
\text { without } \\
\text { activated } \\
\text { charcoal }\end{array}$ & $\begin{array}{c}50 \mu \mathrm{g} \\
1-\mathrm{h} \\
\text { intravenous } \\
\text { solution }\end{array}$ \\
\hline \multicolumn{13}{|l|}{ SRD trial } \\
\hline $\begin{array}{l}\text { Subjects } \\
\text { Adverse event }\end{array}$ & 14 & 6 & 6 & 6 & 6 & 6 & 6 & 6 & & & & \\
\hline $\begin{array}{l}\text { Subjects with any adverse } \\
\text { event }\end{array}$ & $2(14.3)$ & $1(16.7)$ & 0 & $1(16.7)$ & $1(16.7)$ & 2 (33.3) & 0 & $1(16.7)$ & & & & \\
\hline Headache & $1(7.1)$ & $1(16.7)$ & 0 & $1(16.7)$ & 0 & $1(16.7)$ & 0 & 0 & & & & \\
\hline Nasopharyngitis & $1(7.1)$ & 0 & 0 & 0 & 0 & 0 & 0 & $1(16.7)$ & & & & \\
\hline Cough & 0 & 0 & 0 & 0 & $1(16.7)$ & 0 & 0 & 0 & & & & \\
\hline Dry eye & 0 & 0 & 0 & 0 & 0 & $1(16.7)$ & 0 & 0 & & & & \\
\hline $\begin{array}{l}\text { Subjects with drug-related } \\
\text { adverse events }\end{array}$ & 0 & 0 & 0 & 0 & $1(16.7)$ & $1(16.7)$ & 0 & 0 & & & & \\
\hline \multicolumn{13}{|l|}{ MRD trial } \\
\hline Subjects & 10 & & 8 & 8 & 8 & 8 & 8 & & & & & \\
\hline $\begin{array}{l}\text { Subjects with any adverse } \\
\text { event }\end{array}$ & $1(10.0)$ & & 1 (12.5) & $2(25.0)$ & $5(62.5)$ & $4(50.0)$ & $2(25.0)$ & & & & & \\
\hline \multicolumn{13}{|l|}{$\begin{array}{l}\text { Adverse events in } \geqslant 2 \\
\text { subjects }\end{array}$} \\
\hline Headaches & 0 & & 1 (12.5) & 0 & $1(12.5)$ & 0 & $1(12.5)$ & & & & & \\
\hline Diarrhoea & 0 & & 0 & 0 & $2(25.0)$ & 1 (12.5) & 0 & & & & & \\
\hline Oropharyngeal pain & 0 & & 0 & 0 & $2(25.0)$ & 0 & $1(12.5)$ & & & & & \\
\hline Cough & 0 & & 0 & 0 & 0 & $1(12.5)$ & $1(12.5)$ & & & & & \\
\hline Dyspepsia & 0 & & $1(12.5)$ & $1(12.5)$ & 0 & 0 & 0 & & & & & \\
\hline Dizziness & 0 & & 0 & 0 & 0 & $2(25.0)$ & 0 & & & & & \\
\hline $\begin{array}{l}\text { Subjects with drug-related } \\
\text { adverse events }\end{array}$ & 0 & & $1(12.5)$ & $1(12.5)$ & $4(50.0)$ & $4(50.0)$ & 1 (12.5) & & & & & \\
\hline $\begin{array}{l}\text { Subjects with adverse } \\
\text { events leading to } \\
\text { discontinuation of trial drug }\end{array}$ & 0 & & 0 & 0 & 0 & 1 (12.5) & 0 & & & & & \\
\hline \multicolumn{13}{|l|}{ Bioavailability trial } \\
\hline Subjects & & & & & & & & & 12 & 12 & 12 & 12 \\
\hline $\begin{array}{l}\text { Subjects with any adverse } \\
\text { events }\end{array}$ & & & & & & & & & $2(16.7)$ & 0 & $1(8.3)$ & $1(8.3)$ \\
\hline $\begin{array}{l}\text { Subjects with serious } \\
\text { adverse events (neuropathia } \\
\text { vestibularis right) }\end{array}$ & & & & & & & & & $1(8.3)$ & 0 & 0 & 0 \\
\hline $\begin{array}{l}\text { Subjects with drug-related } \\
\text { adverse events }\end{array}$ & & & & & & & & & 0 & 0 & 0 & 0 \\
\hline $\begin{array}{l}\text { Subjects with adverse events } \\
\text { leading to discontinuation of } \\
\text { trial drug }\end{array}$ & & & & & & & & & 0 & 0 & 0 & 0 \\
\hline
\end{tabular}


One subject in the $300 \mu \mathrm{g}$ dose group discontinued from trial drug on day 7 due to hyperkalaemia. A first transient increase of serum potassium was observed on day $3\left(5.69 \mathrm{mmol} \cdot \mathrm{L}^{-1}\right.$; normal range $\left.3.30-5.10 \mathrm{mmol} \cdot \mathrm{L}^{-1}\right)$, with recovery the next day to within normal range $\left(4.95 \mathrm{mmol} \cdot \mathrm{L}^{-1}\right)$. Serum potassium was again above the upper limit of normal following the morning dosing on day 6 $\left(5.91 \mathrm{mmol} \cdot \mathrm{L}^{-1}\right)$ and continued above normal on day $7\left(5.80 \mathrm{mmol} \cdot \mathrm{L}^{-1}\right)$. Treatment with BI 1265162 was stopped on day 7 and the subject recovered within 1 day (day 8: $4.29 \mathrm{mmol} \cdot \mathrm{L}^{-1}, 4.35 \mathrm{mmol} \cdot \mathrm{L}^{-1}$; day 9: $\left.4.85 \mathrm{mmol} \cdot \mathrm{L}^{-1}\right)$. The subject was asymptomatic with no clinical or ECG findings, and no change in other serum electrolytes (sodium, chloride, calcium), serum creatinine, urine aldosterone, urine creatinine or urine electrolytes (sodium, potassium, chloride) was observed concomitantly. This subject had the highest PK plasma BI 1265162 concentration in the $300 \mu \mathrm{g}$ BI 1265162 dose group $\left(3670 \mathrm{pmol} \cdot \mathrm{L}^{-1}\right)$ at $10 \mathrm{~min}$ post-dose on day 7; however, this concentration was lower than the highest observed concentration measured at $10 \mathrm{~min}$ post-dose in the $600 \mu \mathrm{g}$ dose group $\left(8560 \mathrm{pmol} \cdot \mathrm{L}^{-1}\right)$. There were no clinically significant changes in electrolyte concentrations observed following $600 \mu \mathrm{g}$ dosing, with no clinical symptoms or ECG findings. The observed hyperkalaemia in this subject could thus not be explained by the mode of action of ENaC inhibition in the kidney, which should have resulted in changes of the urine electrolytes. In the absence of alternative reasons, the exact reason remains unclear and individual susceptibility of this subject cannot be excluded with the available data.

No other subject had clinically relevant electrolyte changes. No changes or numerical trends were observed by BI 1265162 dose group when compared with placebo for serum electrolytes, urine aldosterone, fractioned urinary creatinine-adjusted sodium or potassium, and for the urinary sodium/potassium ratio, including in the subject showing potassium above the upper limit of normal. No other relevant changes were reported in safety laboratory data, vital signs, 12-lead ECG or spirometry values. No deaths, SAEs or protocol-specific AESIs were reported.

\section{Bioavailability trial}

All treatments were well tolerated by the 12 subjects. All TEAEs (oral $\mathrm{n}=2$; inhaled (without charcoal) $\mathrm{n}=1$; i.v. $\mathrm{n}=1$ ) were of mild or moderate intensity, with the exception of one SAE in the BI 1265162 oral group. This subject had participated uneventfully in the i.v. group, and in the following oral drug exposure, experienced vomiting and a vestibular disorder (reported term: neuropathia vestibularis), which led to hospitalisation. The SAE started on day 1, lasted 24 days, and was assessed as not related to trial medication. The subject recovered and participated afterwards in an inhaled-treatment group without any adverse events, receiving three out of the four planned doses. All adverse events were resolved by trial-end; no deaths or other SAEs were reported. No clinically relevant changes in safety laboratory parameters, vital signs or plasma and urine electrolytes were detected in this trial.

\section{Pharmacokinetics}

The resulting PK parameters from all three clinical trials are summarised in table 4.

Geometric mean (gMean) plasma concentration-time profiles for BI 1265162 in the SRD and MRD trials are shown in figure 2. Following both single and multiple dosing, BI 1265162 was quickly absorbed into the systemic circulation, with a median time from dosing to maximum plasma concentration $\left(\mathrm{C}_{\max }\right)$ of 5-11 min post-dose. Following $\mathrm{C}_{\max }$, plasma BI 1265162 concentrations declined in a multi-exponential manner. Following single inhaled doses of $\geqslant 300 \mu \mathrm{g}$, a slower elimination phase was observed from $\sim 12 \mathrm{~h}$ post-dose, with concentrations at $24 \mathrm{~h}$ post-dose $\sim 1 \%$ of the respective $\mathrm{C}_{\max }$ values. Following the highest single dose $(1200 \mu \mathrm{g})$, where plasma concentrations were measured up to $72 \mathrm{~h}$ post-dose, the observed gMean terminal elimination half-life was $15.5 \mathrm{~h}$. For the lower doses, this terminal phase could not be accurately quantified due to the shorter investigational period of $48 \mathrm{~h}$ and a number of samples being below the bioanalytical assay's lower limit of quantification (LLOQ).

Following twice-daily dosing, steady state was attained post-second dose. There was no apparent accumulation in $\mathrm{C}_{\max }$ values over time following 10,30 and $600 \mu \mathrm{g}$ twice daily, and a relatively small amount of accumulation in $\mathrm{C}_{\max }$ values following $100 \mu \mathrm{g}$ (1.64-fold) and $300 \mu \mathrm{g}$ (1.35-fold) twice daily. The accumulation in area under the curve over the time interval $0-12 \mathrm{~h}\left(\mathrm{AUC}_{0-12}\right)$ was $\sim 1.6$-fold at maximum. The effective elimination half-life, calculated from accumulation and dosing frequency, was calculated to be $\sim 3.6-8.7 \mathrm{~h}$.

Difficulties in capturing the true terminal elimination phase in the SRD, which appeared to start $\sim 12 \mathrm{~h}$ post-dose over the full dose range, meant that different phases of the multi-exponential decline were characterised following the different doses. Post-dose, BI 1265162 concentrations were below the assay's LLOQ from $\sim 1 \mathrm{~h}$ for the $3 \mu \mathrm{g}$ dose, $4 \mathrm{~h}$ for the $10 \mu \mathrm{g}$ dose, $6 \mathrm{~h}$ for the $30 \mu \mathrm{g}$ dose and $\geqslant 12 \mathrm{~h}$ for doses of $\geqslant 100 \mu \mathrm{g}$. Thus, in order to compare the same portion of the concentration-time curve over the full dose range to assess dose proportionality, AUC $0-1 \mathrm{~h}\left(\mathrm{AUC}_{0-1}\right)$ was used instead of $\mathrm{AUC}_{0-\infty}$. $\mathrm{AUC}_{0-1}$ increased 


\begin{tabular}{|c|c|c|c|c|c|c|c|c|c|c|c|}
\hline & $3 \mu \mathrm{g}$ & $10 \mu \mathrm{g}$ & $30 \mu \mathrm{g}$ & $100 \mu g$ & $300 \mu g$ & $600 \mu \mathrm{g}$ & $1200 \mu \mathrm{g}$ & $\begin{array}{l}1.25 \mathrm{mg} \text { oral } \\
\text { solution }\end{array}$ & $\begin{array}{l}200 \mu \mathrm{g} \\
\text { inhaled, } \\
\text { with } \\
\text { activated } \\
\text { charcoal }\end{array}$ & $\begin{array}{l}200 \mu \mathrm{g} \\
\text { inhaled, } \\
\text { without } \\
\text { activated } \\
\text { charcoal }\end{array}$ & $\begin{array}{c}50 \mu \mathrm{g} \\
1-\mathrm{h} \\
\text { intravenous } \\
\text { solution }\end{array}$ \\
\hline \multicolumn{12}{|l|}{ SRD trial } \\
\hline Subjects & $5^{\#}$ & 6 & 6 & 6 & 6 & 6 & 6 & & & & \\
\hline $\begin{array}{l}\mathrm{C}_{\max } \\
\mathrm{pmol} \cdot \mathrm{L}^{-1}\end{array}$ & 17.8 (32.9) & $50.1(46.6)$ & $129(40.1)$ & 462 (53.2) & $1090(26.0)$ & $3130(30.6)$ & $6500(73.1)$ & & & & \\
\hline$t_{\max } \mathrm{h}$ & $\begin{array}{c}0.083 \\
(0.033-0.083)\end{array}$ & $\begin{array}{c}0.083 \\
(0.083-0.167)\end{array}$ & $\begin{array}{c}0.100 \\
(0.083-0.167)\end{array}$ & $\begin{array}{c}0.134 \\
(0.083-0.183)\end{array}$ & $\begin{array}{c}0.167 \\
(0.167-0.183)\end{array}$ & $\begin{array}{c}0.167 \\
(0.083-0.167)\end{array}$ & $\begin{array}{c}0.183 \\
(0.167-0.250)\end{array}$ & & & & \\
\hline $\begin{array}{l}\mathrm{AUC}_{0-1} \\
\mathrm{pmol} \cdot \mathrm{L}^{-1} \cdot \mathrm{h}\end{array}$ & $10.4(42.4)$ & $28.7(49.0)$ & $73.7(43.4)$ & 299 (45.2) & 706 (25.9) & 1700 (34.5) & $3920(76.4)$ & & & & \\
\hline $\begin{array}{l}\mathrm{AUC}_{0-\infty} \\
\mathrm{pmol} \cdot \mathrm{L}^{-1} \cdot \mathrm{h}\end{array}$ & 23.8 (88.2) & 85.7 (55.3) & 208 (37.1) & 959 (45.0) & $2370(23.1)$ & 5820 (38.9) & $13500(65.3)$ & & & & \\
\hline $\begin{array}{l}\mathrm{CL} / \mathrm{F} \\
\mathrm{mL} \cdot \mathrm{min}^{-1}\end{array}$ & 3700 (88.2) & 3430 (55.3) & $4230(37.1)$ & 3070 (45.0) & $3730(23.1)$ & 3030 (38.9) & 2610 (65.3) & & & & \\
\hline$t_{1 / 2} \mathrm{~h}$ & $1.24(76.2)$ & 2.43 (28.5) & 2.70 (35.7) & $4.23(40.2)$ & $6.04(50.0)$ & $10.2(23.2)$ & 15.5 (15.2) & & & & \\
\hline \multicolumn{12}{|l|}{ MRD trial } \\
\hline Subjects & & 8 & 8 & 8 & 8ा & 8 & & & & & \\
\hline \multicolumn{12}{|l|}{ Day 1} \\
\hline $\begin{array}{c}\mathrm{C}_{\max } \\
\mathrm{pmol} \cdot \mathrm{L}^{-1}\end{array}$ & & $55.2(36.1)$ & 158 (27.4) & 391 (24.4) & 1330 (43.5) & 4000 (28.0) & & & & & \\
\hline $\begin{array}{r}\mathrm{AUC}_{0-12} \\
\mathrm{pmol} \cdot \mathrm{L}^{-1} \cdot \mathrm{h}\end{array}$ & & 82.5 (24.5) & $226(23.2)$ & 734 (22.5) & 2430 (35.2) & 6320 (21.3) & & & & & \\
\hline$t_{\max } \mathrm{h}$ & & $\begin{array}{c}0.083 \\
(0.033-0.167)\end{array}$ & $\begin{array}{c}0.083 \\
(0.083-0.167)\end{array}$ & $\begin{array}{c}0.167 \\
(0.083-0.250)\end{array}$ & $\begin{array}{c}0.167 \\
(0.083-0.250)\end{array}$ & $\begin{array}{c}0.150 \\
(0.133-0.233)\end{array}$ & & & & & \\
\hline$t_{1 / 2} \mathrm{~h}$ & & $2.04(29.3)$ & $2.44(16.1)$ & $3.26(23.2)$ & $7.17(15.8)$ & $7.43(19.6)$ & & & & & \\
\hline $\begin{array}{l}f_{\mathrm{e}_{0-12}} \% \\
\text { Day } 8\end{array}$ & & $0.721(37.1)$ & $0.664(49.5)$ & $0.696(66.2)$ & $0.766(65.4)$ & $0.831(39.8)$ & & & & & \\
\hline $\begin{array}{r}C_{\max , s s} \\
\text { pmol. } \mathrm{L}^{-1}\end{array}$ & & 55.6 (25.7) & 143 (38.5) & 640 (42.7) & 1710 (35.5) & 3670 (39.9) & & & & & \\
\hline$t_{\text {max,ss }} \mathrm{h}$ & & $\begin{array}{c}0.083 \\
(0.083-0.167)\end{array}$ & $\begin{array}{c}0.083 \\
(0.083-0.200)\end{array}$ & $\begin{array}{c}0.125 \\
(0.083-0.250)\end{array}$ & $\begin{array}{c}0.167 \\
(0.083-0.250)\end{array}$ & $\begin{array}{c}0.159 \\
(0.117-0.233)\end{array}$ & & & & & \\
\hline $\begin{array}{c}\mathrm{AUC}_{\text {rss }} \\
\mathrm{pmol} \cdot \mathrm{L}^{-1} \cdot \mathrm{h}\end{array}$ & & 104 (18.8) & $284(40.0)$ & $1190(29.4)$ & 3800 (29.3) & $7010(36.4)$ & & & & & \\
\hline$f_{\mathrm{e}_{0-125 s}} \%$ & & $1.06(25.0)$ & 1.14 (32.8) & 1.38 (45.3) & $1.36(54.6)$ & 0.874 (72.9) & & & & & \\
\hline $\mathrm{RA}_{\mathrm{Cmax}_{\max }}$ & & $1.01(32.9)$ & 0.905 (39.8) & 1.64 (32.0) & 1.35 (31.7) & 0.917 (26.9) & & & & & \\
\hline $\mathrm{RA}_{\mathrm{AUC} 0-12}$ & & 1.26 (22.5) & $1.25(28.1)$ & 1.62 (24.5) & $1.60(28.1)$ & $1.11(32.0)$ & & & & & \\
\hline
\end{tabular}




\begin{tabular}{|c|c|c|c|c|c|c|c|c|c|c|c|}
\hline & $3 \mu \mathrm{g}$ & $10 \mu \mathrm{g}$ & $30 \mu \mathrm{g}$ & $100 \mu g$ & $300 \mu \mathrm{g}$ & $600 \mu \mathrm{g}$ & $1200 \mu \mathrm{g}$ & $\begin{array}{l}1.25 \mathrm{mg} \text { oral } \\
\text { solution }\end{array}$ & $\begin{array}{l}200 \mu g \\
\text { inhaled, } \\
\text { with } \\
\text { activated } \\
\text { charcoal }\end{array}$ & $\begin{array}{l}200 \mu g \\
\text { inhaled, } \\
\text { without } \\
\text { activated } \\
\text { charcoal }\end{array}$ & $\begin{array}{c}50 \mu \mathrm{g} \\
1-\mathrm{h} \\
\text { intravenous } \\
\text { solution }\end{array}$ \\
\hline \multicolumn{12}{|l|}{ Bioavailability } \\
\hline $\begin{array}{l}\text { Subjects } \\
\mathrm{C}_{\max } \\
\mathrm{pmol} \cdot \mathrm{L}^{-1}\end{array}$ & & & & & & & & $\begin{array}{c}12 \\
62.5(49.4)\end{array}$ & $\begin{array}{c}12 \\
1910(25.7)\end{array}$ & $\begin{array}{c}12 \\
1800(31.0)\end{array}$ & $\begin{array}{c}12 \\
2040(17.1)\end{array}$ \\
\hline$t_{\max } \mathrm{h}$ & & & & & & & & $\begin{array}{c}0.750 \\
(0.500-1.000)\end{array}$ & $\begin{array}{c}0.167 \\
(0.083-0.250)\end{array}$ & $\begin{array}{c}0.167 \\
(0.167-0.250)\end{array}$ & $\begin{array}{c}0.742 \\
(0.500-0.983)\end{array}$ \\
\hline $\begin{array}{l}\mathrm{AUC}_{0-\infty} \\
\mathrm{pmol} \cdot \mathrm{L}^{-1} \cdot \mathrm{h} \\
\quad \mathrm{AUC} \mathrm{C}_{0-\infty} \\
\mathrm{pmol} \cdot \mathrm{L}^{-1} \cdot \mathrm{h}\end{array}$ & & & & & & & & $277(62.1)$ & $3590(25.5)$ & $3590(20.8)$ & $2230(15.3)$ \\
\hline $\mathrm{F} \%$ & & & & & & & & 0.50 (37.8) & $40.5(20.8)$ & $40.2(16.8)$ & N/A \\
\hline
\end{tabular}

Data are presented as $\mathrm{n}$, geometric mean (geometric coefficient of variance) or median (range), unless otherwise stated. SRD: single-rising-dose; $\mathrm{C}_{\text {max }}$ maximum measured concentration of $\mathrm{BI} 1265162$ in plasma after single dose; $t_{\text {max }}$ : time administered drug excreted from last dosing to the maximum concentration of $\mathrm{BI} 1265162$ in plasma after single dose; $\mathrm{AUC}_{0-1}$ : area under the curve of $\mathrm{BI} 1265162$ in plasma from dosing to $1 \mathrm{~h}$ post-dosing; $\mathrm{AUC}_{0-\infty}$ : area under the concentration-time curve of $\mathrm{BI} 1265162$ in plasma over the time interval from 0 extrapolated to infinity: $\mathrm{CL} / \mathrm{F}$ : apparent clearance; $t_{1 / 2}$ : observed terminal elimination half-life of $\mathrm{BI} 1265162$ in plasma; $\mathrm{MRD}$ : multiple-rising-dose: AUC $\mathrm{C}_{0-12:}$ area under the curve of $\mathrm{Bl} 1265162$ in plasma over a 12-h period after single dose; $f_{\mathrm{e}_{0-1}}$ : fraction of administered drug excreted unchanged in urine over a 12 -h period after single dose; $\mathrm{C}_{\text {max,ss: }}$ maximum measured concentration of BI 1265162 in plasma at steady state; $t_{\text {max,ss: }}$ : time administered drug excreted from last dosing to the maximum concentration of BI 1265162 in plasma at steady state; $\mathrm{AUC}_{\tau, \mathrm{ss}}$ : area under the curve of $\mathrm{BI} 1265162$ in plasma over a 12-h period at steady state; $f_{\mathrm{e}_{0-12.5}}$ : fraction of administered drug excreted unchanged in urine over a

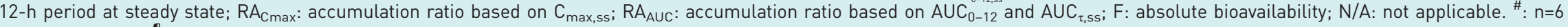
for $\mathrm{C}_{\max }$ and $t_{\max }{ }^{\text {ๆ }: \mathrm{n}=7 \text { on day } 8 .}$ 

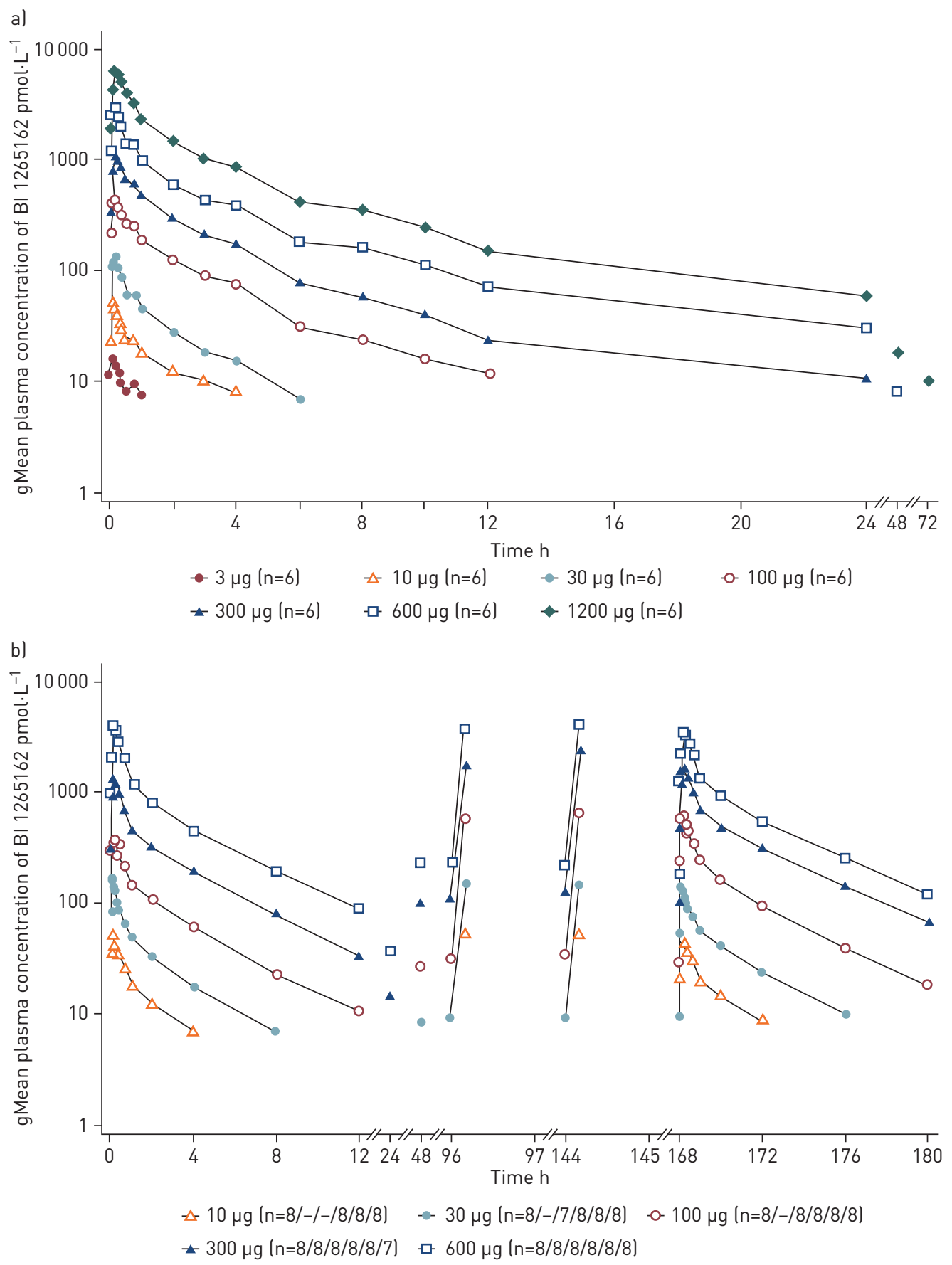

FIGURE 2 Geometric mean plasma concentration-time profiles of BI 1265162 in a) the single-rising-dose trial and b) the multiple-rising-dose trial (doses given twice daily). gMean: geometric mean.

in a dose-proportional manner over 3-1200 $\mu$ g. Following twice-daily dosing in the MRD, $\mathrm{AUC}_{0-12}$ could be estimated more accurately over the 12-h investigational period over the 10-600 $\mu$ g dose range investigated. Both $\mathrm{C}_{\max }$ and $\mathrm{AUC}_{0-12}$ increased in a dose-proportional manner on day 1 following a single dose and at steady state following twice-daily dosing $(10-600 \mu \mathrm{g})$. This was confirmed by statistical evaluation as the point estimate for the slope $\beta$ was close to 1 and the $95 \%$ confidence interval included 1 for all PK parameters tested. For doses $\geqslant 100 \mu \mathrm{g}$, trough concentrations ( $12 \mathrm{~h}$ post-dose) were approximately $\leqslant 6 \%$ of the respective $C_{\max }$ values for each subject. Over the entire 6.5-day investigational period of twice-daily dosing, the gMean (geometric coefficient of variance $(\mathrm{gCV})$ ) fraction of drug excreted unchanged in urine over a 12-h period was very low for all dose groups (30 $\mu \mathrm{g} 0.664 \%$ (49.5\%) to $100 \mu \mathrm{g} 1.38 \%$ (45.3\%)). 


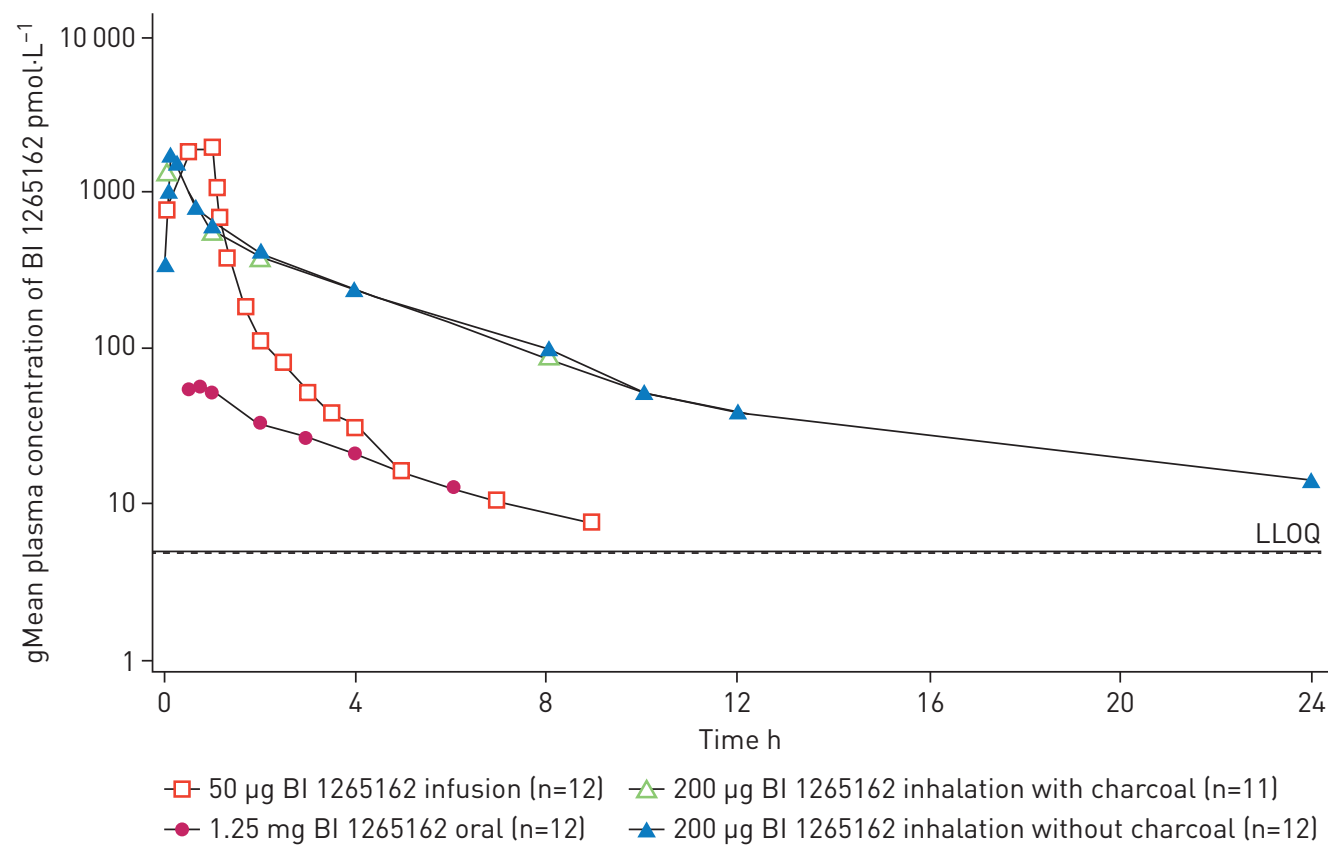

FIGURE 3 Comparison of geometric mean (gMean) plasma concentration-time profiles of BI 1265162 after single administration of $\mathrm{BI} 1265162$ following oral administration $(1.25 \mathrm{mg})$, inhalation with and without charcoal $(200 \mu \mathrm{g})$ and intravenous infusion $(50 \mu \mathrm{g}$ ) (semi-logarithmic scale). LLOQ: lower limit of quantification.

A comparison of gMean plasma concentration-time profiles after a single oral, inhaled ( \pm oral activated charcoal) and i.v. administration of BI 1265162 is shown in figure 3. The absolute bioavailability of BI 1265162 following an oral dose of $1.25 \mathrm{mg}$, estimated as ratio of dose-normalised $\mathrm{AUC}_{0-\infty}$ gMeans (gCV) for oral versus i.v. administration, was $0.50 \%(37.8 \%)$, whereas the absolute bioavailability (gMean (gCV)) following inhalation of $200 \mu \mathrm{g}$ BI 1265162 was 40.5\% (20.8\%) with activated charcoal and 40.2\% (16.8\%) without. The activated charcoal in the gastrointestinal tract absorbs the drug, thus preventing oral absorption of BI 1265162 into the systemic circulation. This indicates that systemic BI 1265162 exposure represents drug absorbed mainly from the lung.

\section{Discussion}

Inhibition of ENaC could restore ASL hydration and enhance mucociliary clearance, and is therefore a promising therapeutic option for patients with $\mathrm{CF}$. In addition, $\mathrm{ENaC}$ inhibition may have a synergistic effect with CFTR modulators [9], which restore 10-50\% of CFTR function [6-8]. As such, ENaC inhibition could offer a mutation-agnostic approach [9] with therapeutic benefit for all CF patients, irrespective of CFTR genotype or treatment with CFTR modulators. Importantly, in patients who receive CFTR modulator therapy, ENaC inhibition could help to achieve optimal treatment benefit.

We carried out three phase I trials of the inhaled ENaC inhibitor BI 1265162 to assess safety, PK and bioavailability. All tested doses of BI 1265162 were found to be safe and well tolerated in healthy male subjects when administered following single or twice-daily dosing for up to 6.5 days, with adverse events balanced across all groups. All adverse events were of mild or moderate intensity and resolved by trial-end. One subject in the MRD trial experienced hyperkalaemia on day 3, returned to normal during treatment and then increased again, leading to premature discontinuation from the trial drug on day 7 due to an adverse event (hyperkalaemia). The subject recovered within 1 day after treatment discontinuation. All other subjects, except one additional subject (in the bioavailability trial who received three of the four planned doses (the oral dose was missed)), received the trial medication as planned and completed the trial. This subject experienced an SAE (neuropathia vestibularis) leading to hospitalisation. The SAE was not considered drug-related and after recovery, the subject continued in an inhaled-treatment group without reporting any further adverse events. Assessment of palatability and acceptability did not show relevant differences to placebo in the SRD trial, and all but one of the subjects indicated that they would take the medication long term.

Previous clinical development of $\mathrm{ENaC}$ inhibitors has been hampered by a number of barriers, including systemic side-effects (chiefly the induction of hyperkalaemia as a result of the high levels of ENaC expression in the cortical collecting duct of the kidney) [20]. It is therefore crucial that any ENaC-blocking 
therapy for CF maximises effects in the lung while minimising off-target effects, including ENaC inhibition in the kidneys. In our MRD trial, the subject with hyperkalaemia was asymptomatic, no clinical abnormality was noted in vital signs, especially ECG, and no changes in creatinine clearance were noted. If a blockade of the renal $\mathrm{ENaC}$ was involved, a decrease in urine potassium and an increase in urinary sodium and aldosterone could be expected based on the mode of action. However, this was not observed in this subject, whose BI 1265162 PK concentrations and exposures were lower than the highest exposures observed in the higher $600 \mu \mathrm{g}$ dose group, where no electrolyte changes were observed. No other changes in serum electrolytes, no symptoms or changes in ECG were seen in this subject with a maximum serum potassium at day 6 of $5.91 \mathrm{mmol} \cdot \mathrm{L}^{-1}$. In addition, no serum electrolyte changes were observed following the 1-h infusion of $50 \mu \mathrm{g}$ BI 1265162 in the bioavailability trial, where gMean $\mathrm{C}_{\max }$ values were higher than those observed at steady state following inhaled doses of $300 \mu \mathrm{g}$ twice daily in the MRD trial, whereas gMean $\mathrm{AUC}_{0-\infty}$ and $\mathrm{AUC}_{0-12}$ values were of similar magnitude following both doses. The reason for this hyperkalaemia remains unclear. Corresponding changes in urine electrolytes are missing and the renal function was stable and normal. It cannot be excluded that individual reasons or susceptibility contributed to the event.

Following inhaled dosing, BI 1265162 was eliminated more slowly from the systemic circulation than after i.v. dosing (see the shallower slope after $\mathrm{C}_{\max }$ in figure 3). This suggests that this phase represents the absorption of drug from the lungs, rather than the elimination of drug from the body, indicating flip-flop kinetics. In this situation, absorption of drug from the lungs is the rate-limiting step. Therefore, the compound's elimination phase becomes dependent on absorption rather than elimination. The oral bioavailability (gMean) of BI 1265162 through the gastrointestinal tract was very low: $\sim 0.5 \%$ compared with the bioavailability following inhalation, which was $\sim 40 \% \pm$ oral activated charcoal, administered preand post-inhaled dosing. This indicates that systemic BI 1265162 drug concentrations and exposures following inhalation predominately represent drug absorbed from the lung.

BI 1265162 showed dose-proportional PK following both single and twice-daily dosing, with steady state achieved following the second twice daily dose and minimal accumulation. Due to the multi-exponential decline of BI 1265162 observed in the SRD trial, where the true terminal elimination phase appears to start around $12 \mathrm{~h}$ post-dose, the selection of $\mathrm{AUC}_{0-1}$ instead of $\mathrm{AUC}_{0-\infty}$ for evaluation of dose proportionality permitted almost all subjects to be included in the analysis, confirming dose proportionality over the complete dose range tested.

The amount of BI 1265162 excreted unchanged in the urine at steady state was $<1.4 \%$ of the inhaled dose, showing that renal excretion is not a major elimination route for BI 1265162. Data from rat studies indicate that hepatic elimination is the major route of elimination. A human absorption, metabolism and elimination study is planned to investigate the major routes of elimination.

A potential limitation of this study, as is common with phase I studies in general, is that healthy volunteers were recruited. It is possible that the PK properties of BI 1265162 may be different in healthy volunteers as compared with patients with CF. However, previous studies of a compound related to BI 1265162 demonstrated that PK properties were similar in healthy volunteers and patients with CF (data on file).

In conclusion, results from phase I trials showed that SRDs of BI $1265162 \leqslant 1200 \mu \mathrm{g}$ and MRDs of $10 \mu \mathrm{g}$, $30 \mu \mathrm{g}, 100 \mu \mathrm{g}, 300 \mu \mathrm{g}$ and $600 \mu \mathrm{g}$ were safe and well tolerated in healthy male subjects. Following twice-daily inhalation, BI 1265162 showed dose-linear and time-independent PK within the tested dose ranges. Accumulation was 1.6-fold at maximum. Systemic BI 1265162 drug exposures (given by $\mathrm{C}_{\max }$, $\mathrm{AUC}_{0-\infty}$ and $\mathrm{AUC}_{0-1}$ ) represent drug absorbed through the lungs and not through the gastrointestinal tract. BI 1265162 entered phase II clinical development as described in a separate article in ERJ Open Research [23].

Acknowledgements: Statistical analysis for the bioavailability trial was carried out by Kathrin Hohl on behalf of Boehringer Ingelheim. Editorial assistance in the development of the manuscript was provided by Lee Kempster at MediTech Media, funded by Boehringer Ingelheim.

Conflict of interest: A. Mackie is an employee of Boehringer Ingelheim. J. Rascher has nothing to disclose. M. Schmid is an employee of Boehringer Ingelheim. V. Endriss is an employee of Boehringer Ingelheim. T. Brand is an employee of Boehringer Ingelheim. W. Seibold is an employee of Boehringer Ingelheim.

Support statement: The studies were supported by Boehringer Ingelheim. Funding information for this article has been deposited with the Crossref Funder Registry.

\section{References}

1 Riordan J, Rommens J, Kerem B, et al. Identification of the cystic fibrosis gene: cloning and characterization of complementary DNA. Science 1989; 245: 1066-1073. 
2 Strug LJ, Stephenson AL, Panjwani N, et al. Recent advances in developing therapeutics for cystic fibrosis. Hum Mol Genet 2018; 27: R173-R186.

3 Clancy JP. Rapid therapeutic advances in CFTR modulator science. Pediatr Pulmonol 2018; 53: S4-S11.

4 Middleton PG, Mall MA, Dřevínek P, et al. Elexacaftor-tezacaftor-ivacaftor for cystic fibrosis with a single Phe508del allele. N Engl J Med 2019; 381: 1809-1819.

5 Heijerman HGM, McKone EF, Downey DG, et al. Efficacy and safety of the elexacaftor plus tezacaftor plus ivacaftor combination regimen in people with cystic fibrosis homozygous for the F508del mutation: a double-blind, randomised, phase 3 trial. Lancet 2019; 394: 1940-1948.

6 Guimbellot J, Sharma J, Rowe SM. Toward inclusive therapy with CFTR modulators: progress and challenges. Pediatr Pulmonol 2017; 52: S4-S14.

7 Graeber SY, Dopfer C, Naehrlich L, et al. Effects of lumacaftor-ivacaftor therapy on cystic fibrosis transmembrane conductance regulator function in Phe508del homozygous patients with cystic fibrosis. Am J Respir Crit Care Med 2018; 197: 1433-1442.

8 Graeber SY, Hug MJ, Sommerburg O, et al. Intestinal current measurements detect activation of mutant CFTR in patients with cystic fibrosis with the G551D mutation treated with ivacaftor. Am J Respir Crit Care Med 2015; 192: $1252-1255$.

9 Moore PJ, Tarran R. The epithelial sodium channel $(\mathrm{ENaC})$ as a therapeutic target for cystic fibrosis lung disease. Expert Opin Ther Targets 2018; 22: 687-701.

10 Althaus M. ENaC inhibitors and airway re-hydration in cystic fibrosis: state of the art. Curr Mol Pharmacol 2013 6: 3-12.

11 Mall M, Bleich M, Greger R, et al. The amiloride-inhibitable $\mathrm{Na}^{+}$conductance is reduced by the cystic fibrosis transmembrane conductance regulator in normal but not in cystic fibrosis airways. J Clin Invest 1998; 102: 15-21.

12 Knowles M, Gatzy J, Boucher R. Increased bioelectric potential difference across respiratory epithelia in cystic fibrosis. N Engl J Med 1981; 305: 1489-1495.

13 Boucher RC, Stutts MJ, Knowles MR, et al. $\mathrm{Na}^{+}$transport in cystic fibrosis respiratory epithelia. Abnormal basal rate and response to adenylate cyclase activation. J Clin Invest 1986; 78: 1245-1252.

14 O'Sullivan BP, Freedman SD. Cystic fibrosis. Lancet 2009; 373: 1891-1904.

15 Agrawal PB, Wang R, Li HL, et al. The epithelial sodium channel is a modifier of the long-term nonprogressive phenotype associated with F508del CFTR mutations. Am J Respir Cell Mol Biol 2017; 57: 711-720.

16 Nickolaus P, Jung B, Sabater J, et al. Preclinical evaluation of the ENaC inhibitor BI 1265162 for treatment of cystic fibrosis. ERJ Open Res 2020; 6: 00429-2020.

17 Mall MA. ENaC inhibition in cystic fibrosis: potential role in the new era of CFTR modulator therapies. Eur Respir J 2020; 56: 2000946.

18 Pons G, Marchand MC, d'Athis P, et al. French multicenter randomized double-blind placebo-controlled trial on nebulized amiloride in cystic fibrosis patients. The Amiloride-AFLM Collaborative Study Group. Pediatr Pulmonol 2000; 30: 25-31.

19 Hirsh AJ, Sabater JR, Zamurs A, et al. Evaluation of second generation amiloride analogs as therapy for cystic fibrosis lung disease. J Pharmacol Exp Ther 2004; 311: 929-938.

20 O'Riordan TG, Donn KH, Hodsman P, et al. Acute hyperkalemia associated with inhalation of a potent ENaC antagonist: phase 1 trial of GS-9411. J Aerosol Med Pulm Drug Deliv 2014; 27: 200-208.

21 Rowe SM, Reeves G, Hathorne H, et al. Reduced sodium transport with nasal administration of the prostasin inhibitor camostat in subjects with cystic fibrosis. Chest 2013; 144: 200-207.

22 Dalby RN, Eicher J, Zierenberg B. Development of Respimat ${ }^{\circ}$ Soft Mist ${ }^{\mathrm{TM}}$ Inhaler and its clinical utility in respiratory disorders. Med Devices 2011; 4: 145-155.

23 Goss $\mathrm{CH}$, Jain R, Seibold W, et al. An innovative phase II trial to establish proof of efficacy and optimal dose of a new inhaled ENaC inhibitor BI 1265162 in adults and adolescents with cystic fibrosis (BALANCE-CF ${ }^{\mathrm{TM}} 1$ ). ERJ Open Res 2020; 6: 00395-2020. 